The Journal of Laryngology \& Otology

http://journals.cambridge.org/JLO

Additional services for The Journal of Laryngology \& Otology:

Email alerts: $\underline{\text { Click here }}$

Subscriptions: $\underline{\text { Click here }}$

Commercial reprints: $\underline{\text { Click here }}$

Terms of use : $\underline{\text { Click here }}$

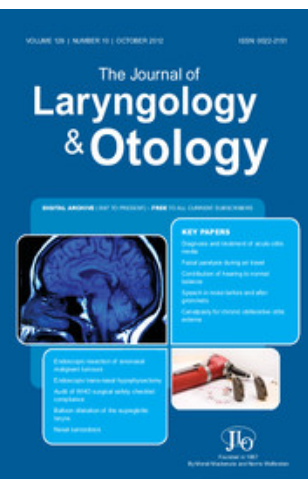

\title{
Large endolymphatic sac. A congenital deformity of the inner ear shown by magnetic resonance imaging
}

P. D. Phelps, C. F. O. Mahoney and L. M. Luxon

The Journal of Laryngology \& Otology / Volume 111 / Issue 08 / August 1997, pp 754 - 756

DOI: 10.1017/S0022215100138538, Published online: 29 June 2007

Link to this article: http://journals.cambridge.org/abstract_S0022215100138538

How to cite this article:

P. D. Phelps, C. F. O. Mahoney and L. M. Luxon (1997). Large endolymphatic sac. A congenital deformity of the inner ear shown by magnetic resonance imaging. The Journal of Laryngology \& Otology, 111, pp 754-756 doi:10.1017/ S0022215100138538

Request Permissions : $\underline{\text { Click here }}$ 


\title{
Large endolymphatic sac. A congenital deformity of the inner ear shown by magnetic resonance imaging
}

\author{
P. D. PhelPS, M.D., F.R.C.S., F.R.C.R., D.M.R.D.*, C. F. O. MAHONEY, M.Sc., M.R.C.P.I.†, \\ L. M. Luxon, B.Sc., M.B., B.S., F.R.C.P.
}

\begin{abstract}
Fluctuant and progressive hearing impairment in a patient with a wide vestibular aqueduct has been called the 'large vestibular aqueduct syndrome'. Recently reports of magnetic resonance imaging (MRI) studies describe enlargement of the endolymphatic sac and duct in patients shown to have large vestibular aqueducts by computed tomography $(\mathrm{CT})$. A patient with progressive deafness was shown to have borderline or slightly enlarged vestibular aqueducts by re-formatted sagittal CT. However, MRI in axial and sagittal planes gave a more satisfactory demonstration of both aqueduct and endolymphatic sac enlargement.
\end{abstract}

\section{Key words: Magnetic resonance imaging; Tomography, X-ray computed; Vestibular aqueduct}

\section{Introduction}

In 1791, Carlo Mondini of Bologna dissected the temporal bones of a boy born deaf and described, with clear illustrations, the cochlear deformity of one turn and a distal sac, which is now called the 'Mondini deformity' (Mondini, 1791). In addition, there was also a very large vestibular aqueduct $16 \mathrm{~mm}$ wide and an enormous endolymphatic sac which Mondini opened.

The first histological section of the temporal bones of a case of Pendred syndrome (Hvidberg-Hansen and BalslevJorgensen, 1986), also showed a large vestibular aqueduct and endolymphatic sac, as well as a Mondini cochlear deformity. Subsequently, imaging has demonstrated the

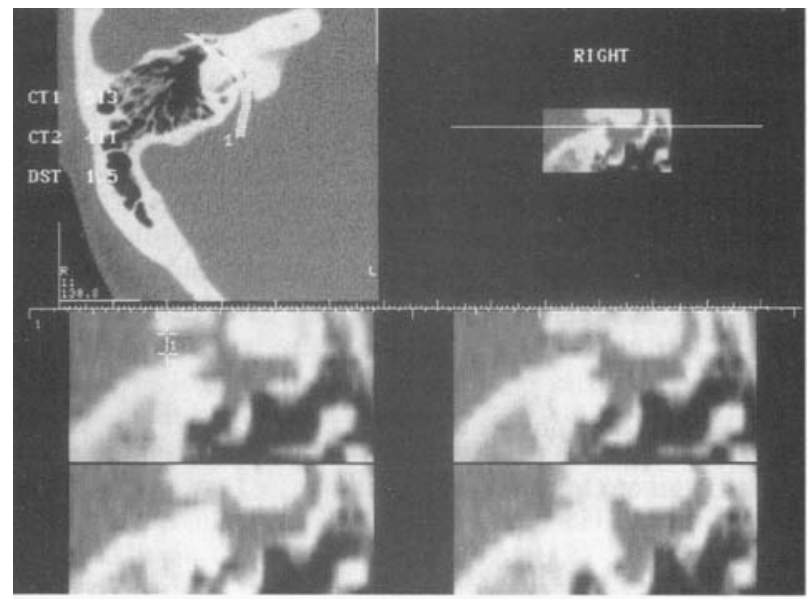

(a) presence of large vestibular aqueducts in patients with hearing impairment; the first description being by Valvassori and Clemis (1978) who defined the large vestibular aqueduct as being more than $1.5 \mathrm{~mm}$ in diameter in the mid-portion of the descending limb of the vestibular aqueduct. They used the term 'vestibular aqueduct syndrome' to describe the characteristic associated clinical features of progressive/fluctuant sensorineural hearing loss often secondary to minor head trauma. Subsequently, the ease with which an LVA can be demonstrated by axial CT has meant that a plethora of accounts of large vestibular aqueduct based on CT has been published, such as those of Emmett (1985) and Levenson et al. (1989). Recently,

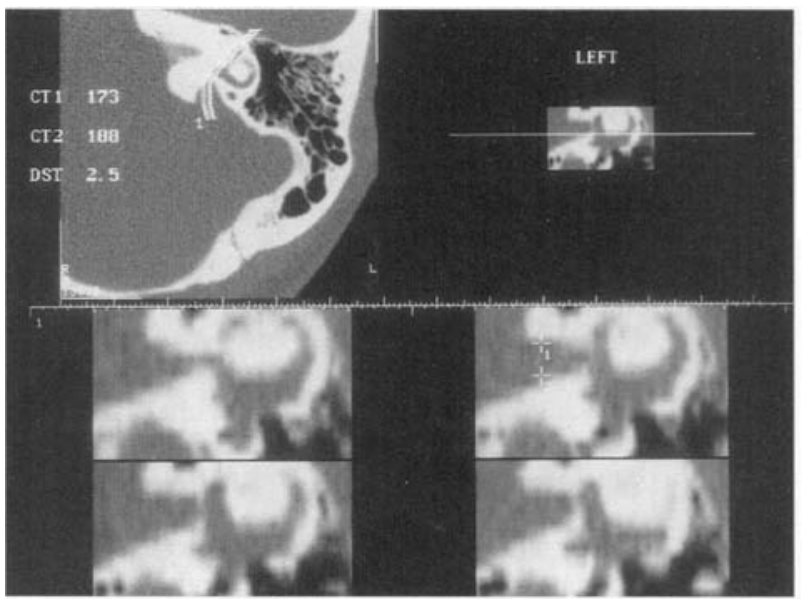

(b)

FIG. $1 \mathrm{a}$ and $\mathrm{b}$

Large vestibular aqueducts shown by axial CT and pre-targeted sections in a slightly off sagittal plane enable measurements to be made in the mid-portion of the descending limb. The right side is at the upper limit of normal $(1.5 \mathrm{~mm})$, the left is enlarged $(2.5 \mathrm{~mm})$.

From the Department of Radiology*. Royal National Throat, Nose and Ear Hospital, the Department of Audiological Medicine $\dagger$. Great Ormond Street Hospital for Children and the Institute of Laryngology and Otology‡, London, UK. Accepted for publication: 11 June 1997. 


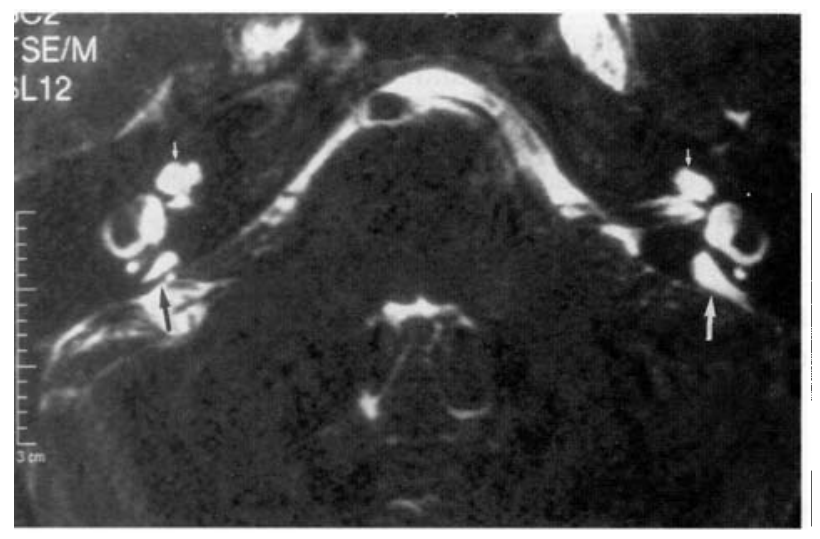

FIG. $2 \mathrm{a}$

Axial thin MRI section shows bilateral Mondini cochleae (small arrows) also large endolymphatic sacs bigger on the left (large white arrow) than the right (black arrow).

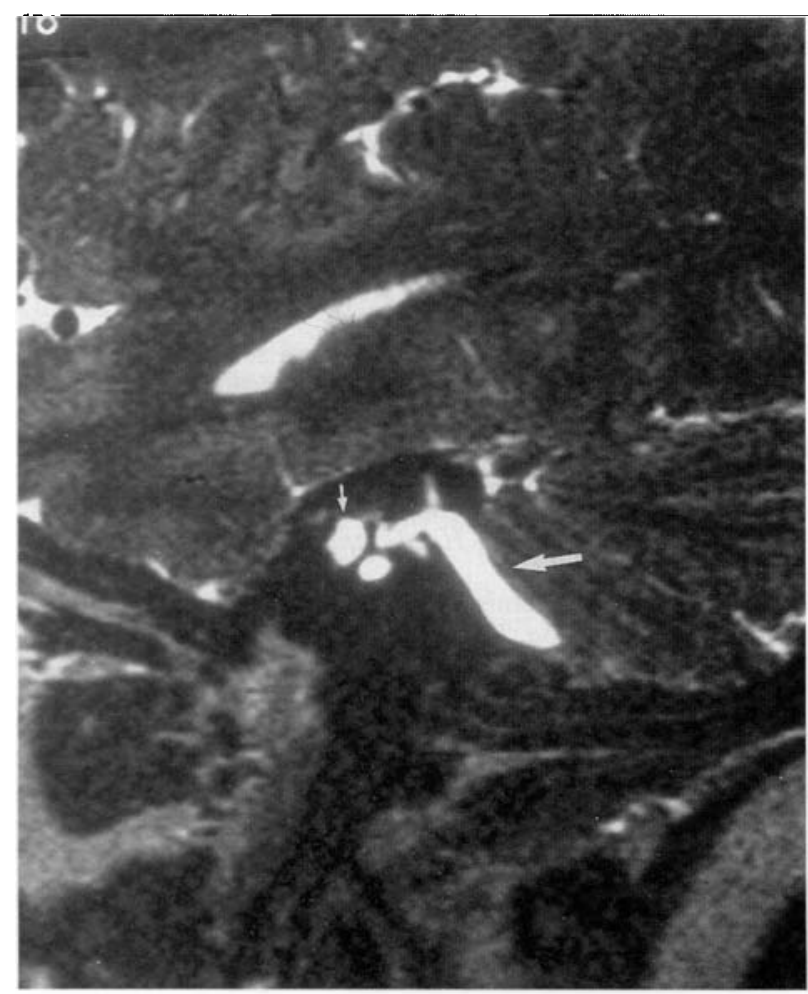

Fig. $2 b$

Sagittal view of the large endolymphatic sac and duct on the left (large arrow) and Mondini cochlea (small arrow).

significant advances in MRI have meant that it is now possible with the latest thin section high resolution techniques to demonstrate the fluid-filled endolymphatic sac and duct.

Moreover it would seem that enlargement of the vestibular aqueduct does not have any sort of constant relation to an enlarged endolymphatic duct and sac. In one series, three cases (five inner ears) with enlarged bony vestibular aqueducts on CT showed no evidence of endolymphatic duct or sac enlargement on MRI. MRI alone identified a single case of mild cochlear anomaly in conjunction with an enlarged endolymphatic duct and sac (Harnsberger et al., 1995). Another case report showed massive endolymphatic sacs on an MR study (Reussner et al., 1995). However, the first report of large endolymphatic sacs shown by MRI as well as large vestibular

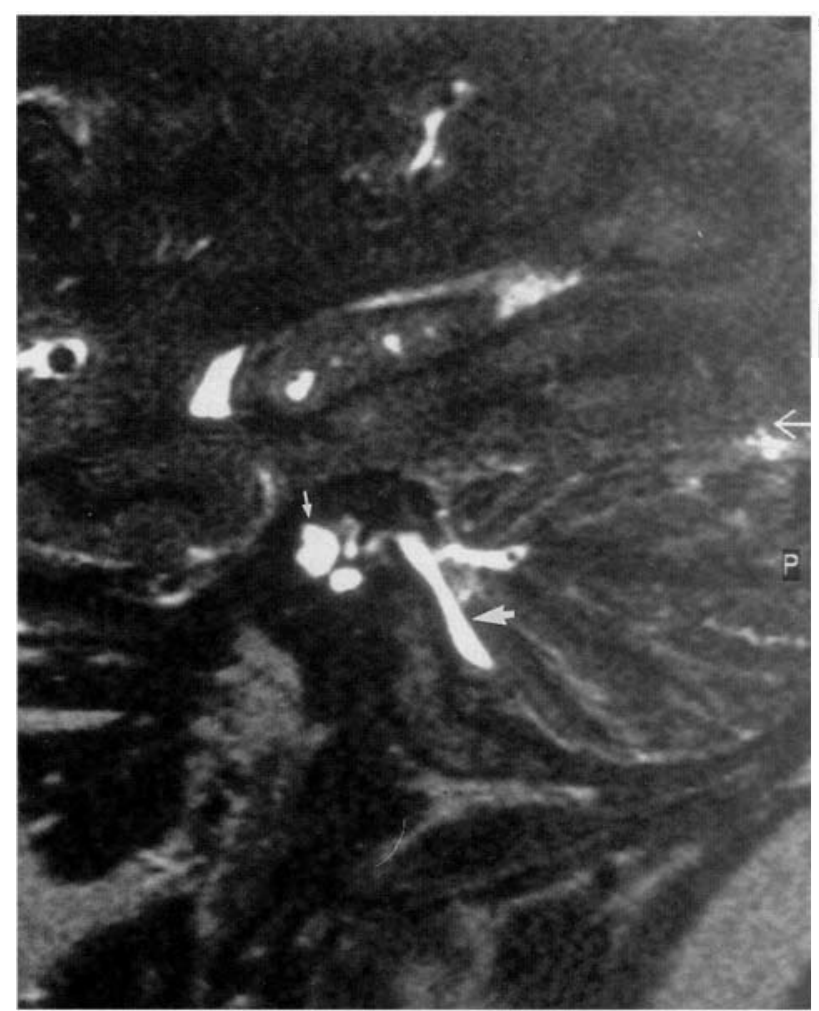

FIG. 2c

Similar view of the right inner ear.

aqueducts demonstrated by CT seems to have been by Hirsch et al. (1992). This was in a patient with all the clinical features of large vestibular aqueduct syndrome.

\section{Case report}

A 35-year-old woman was initially diagnosed as having bilateral severe symmetrical sensorineural hearing loss at the age of three years, thought to be of genetic but progressive origin as her early speech development was normal, but then deteriorated. There was no family history of hearing loss. Initially, she had no symptoms of dizziness/ imbalance but then in the last two years has noted dizziness exacerbated by head movements and changes in posture and deterioration in her hearing. Pure tone audiogram at the time of referral showed deterioration in her hearing bilaterally in comparison with her childhood audiograms. She now has profound bilateral hearing loss. She had no dysmorphic features and no goitre. Clinical vestibular testing was normal although electro-oculography showed second degree right-sided spontaneous nystagmus in the dark and a right directional preponderance on impulsive rotation. A bithermal caloric test did not show a significant abnormality, but the overall conclusion is that she has normal central vestibular function but mild right peripheral dysfunction. In view of the association of widened vestibular aqueducts in Pendred's (1896) syndrome, a thyroid function test and a perchlorate discharge test were performed despite the absence of a palpable goitre. The thyroid function test was normal and a thyroid antibody screen was negative. A perchlorate discharge of 10 per cent (upper limit of normal) was obtained thus making a diagnosis of Pendred's syndrome unlikely. In addition, branchio-oto-renal syndrome (Chen et al., 1995) has also been reported to be associated with a wide vestibular aqueduct and cochlear hypoplasia, but this diagnosis is also unlikely in view of the absence of pits, pinna anomalies or branchial clefts or fistulae. 
CT of the skull base in the axial plane with sections $1 \mathrm{~mm}$ thick showed a probable slight deficiency of the distal part of the interscalar septum of the cochlea on both sides (Mondini deformity). There also seemed to be a wide vestibular aqueduct on both sides although reformatted sections in the plane of the vestibular aqueduct slightly off sagittal showed measurements of $1.5 \mathrm{~mm}$ in the midportion of the descending limb on the right (i.e. within normal limits) but $2.5 \mathrm{~mm}$ on the left (Figure 1). A thin $0.7 \mathrm{~mm}$ section MRI study using a turbo spin echo regime was then used to confirm the Mondini cochlea and large vestibular aqueduct deformities. This examination showed large endolymphatic sacs and ducts on both sides, the left sac being larger than the right (Figure 2).

\section{Discussion}

The large vestibular aqueduct syndrome is now a well recognized condition of progressive and fluctuant hearing loss associated with an enlarged aqueduct. This was shown initially by polytomography and subsequently by CT although the necessity of obtaining sections in the sagittal plane to enable measurement of the mid-portion of the descending limb is a disadvantage of this examination. Only recently have advances in MRI made it possible to assess the bone detail of the vestibular aqueduct almost as well as by CT but much more to the point it is now possible to demonstrate clearly the soft tissue structures within the vestibular aqueduct; namely the endolymphatic sac and duct. The normal endolymphatic duct and sac, however, is of such small calibre that usually it cannot be seen or measured, as in 25 per cent of the normal control inner ears in Harnsberger's series (Harnsberger et al., 1995). Although a large endolymphatic sac and duct shown by MRI is usually associated with an enlarged vestibular aqueduct shown on CT, this is not always the case and the present reported case seems entirely similar to that shown in Figure 3 of Harnsberger's report. These cases with bilateral sensorineural hearing loss were associated with enlarged endolymphatic sacs shown by MRI. As the CT revealed only a unilaterally enlarged vestibular aqueduct we would agree that MRI appears to show a truer picture of the 'vestibular aqueduct syndrome'. Although CT will probably continue as the initial imaging investigation for the assessment of the deaf infant or child because of the overall portrayal of middle and inner ear bony abnormalities, nevertheless there would seem a strong case for using MRI initially for those patients where the loss is definitely sensorineural and especially those with characteristic fluctuant and progressive features occurring in the 'vestibular aqueduct syndrome'. The endolymphatic sac and duct are demonstrated best in the sagittal plane.

\section{References}

Chen, A., Francis, M., Ni, L., Cremers, C. W., Kimberling, W. J., Sato, Y., Phelps, P. D., Bellman, S. C., Wagner, M. J., Pembrey, M. (1995) Phenotypic manifestations of branchiooto-renal syndrome. American Journal of Medical Genetics 58(4): $365-370$.

Emmett, J. R. (1985) The large vestibular aqueduct syndrome. American Journal of Otology 6: 387-403.

Harnsberger, H. R., Dahlen, R. T., Shelton, C., Gray, S. D., Parkin, J. L. (1995) Advanced techniques in magnetic resonance imaging in the evaluation of the large endolymphatic duct and sac syndrome. Laryngoscope 105: 1037-1042.

Hirsch, B. E., Weissman, J. L., Curtin, H. D., Kamerer, D. B. (1992) Magnetic resonance imaging of the large vestibular aqueduct. Archives of Otolaryngology-Head and Neck Surgery 118: 1124-1127.

Hvidberg-Hansen, J., Balslev-Jorgensen, M. (1986) The inner ear in Pendred's syndrome. Acta Otolaryngologica (Stockh) 102: $239-247$.

Levenson, M. J., Parisier, S. C., Jacomb, M., Edelstein, D. R. (1989) The large vestibular aqueduct syndrome in children. Archives of Otolaryngology-Head and Neck Surgery 115: 54-58.

Mondini, C. (1791) Anatomica surdi nati sectio, Bononiensis scientarium et artium instituto atque academia commentarii, Bononiae VII: $419-428$.

Pendred, V. (1896) Deaf-mutism and goitre. Lancet II: 532.

Reussner, L. A., Dutcher, P. O., House, W. F. (1995) Large vestibular aqueduct syndrome with massive endolymphatic sacs. Otolaryngology-Head and Neck Surgery 113: 606-610.

Valvassori, G. E., Clemis, J. D. (1978) The large vestibular aqueduct syndrome. Laryngoscope 88: 723-728.

Address for correspondence:

Dr P. D. Phelps, M.D., F.R.C.S., F.R.C.R., D.M.R.D.,

Consultant Radiologist,

The Royal National Throat, Nose and Ear Hospital,

Gray's Inn Road,

London WC1X 8DA. 